\title{
Metal oxide nanostructures: preparation, characterization and functional applications as chemical sensors
}

\author{
Dario Zappa, Angela Bertuna, Elisabetta Comini", Navpreet Kaur, Nicola Poli, \\ Veronica Sberveglieri and Giorgio Sberveglieri
}

\author{
Full Research Paper \\ Address: \\ SENSOR, Dipartimento di Ingegneria dell'Informazione, Università \\ degli Studi di Brescia and CNR-INO, via Valotti 9, 25123 Brescia, Italy \\ Email: \\ Elisabetta Comini* - elisabetta.comini@unibs.it \\ * Corresponding author \\ Keywords: \\ chemical sensors; electronic nose; metal oxides; nanowires
}

\author{
Beilstein J. Nanotechnol. 2017, 8, 1205-1217. \\ doi:10.3762/bjnano.8.122 \\ Received: 13 July 2016 \\ Accepted: 28 April 2017 \\ Published: 06 June 2017 \\ This article is part of the Thematic Series "Functional materials for \\ environmental sensors and energy systems". \\ Guest Editor: M. Penza
}

(C) 2017 Zappa et al.; licensee Beilstein-Institut.

License and terms: see end of document.

\begin{abstract}
Preparation and characterization of different metal oxide $\left(\mathrm{NiO}, \mathrm{WO}_{3}, \mathrm{ZnO}, \mathrm{SnO}_{2}\right.$ and $\left.\mathrm{Nb}_{2} \mathrm{O}_{5}\right)$ nanostructures for chemical sensing are presented. p-Type $(\mathrm{NiO})$ and n-type $\left(\mathrm{WO}_{3}, \mathrm{SnO}_{2}, \mathrm{ZnO}\right.$ and $\left.\mathrm{Nb}_{2} \mathrm{O}_{5}\right)$ metal oxide nanostructures were grown on alumina substrates using evaporation-condensation, thermal oxidation and hydrothermal techniques. Surface morphologies and crystal structures were investigated through scanning electron microscopy and Raman spectroscopy. Furthermore, different batches of sensors have been prepared, and their sensing performances towards carbon monoxide and nitrogen dioxide have been explored. Moreover, metal oxide nanowires have been integrated into an electronic nose and successfully applied to discriminate between drinking and contaminated water.
\end{abstract}

\section{Introduction}

Nanotechnology is the base for improving knowledge about materials and phenomena at the nanometric scale. This is crucial for the development of any device. Because sensors are able to acquire chemical information from the surroundings in real time, they are attracting a lot of interest and, therefore, they are going to have an increasing impact on everyday life. Chemical sensors may detect toxic analytes and explosives, be integrated in security systems to protect workers from chemical hazards, be used for environmental or health and wealth monitoring, and for food-chain control. In the last years, much effort has been

taken to increase the quality and security of the food chain, since the ingestion of food not properly stored or treated is one of the most frequent reason of hospitalization [1].

Chemical sensors may play a pivotal role in all these applications. Metal oxides were the first to be commercialized as conductometric chemical sensors in form of thick films, and they are still the most promising materials for chemical sensing $[2,3]$. Metal oxide chemical sensors are more stable and reproducible compared to organic sensors. However, in order to be 
used in real cases, these devices need to meet many requirements such as high sensing performances in terms of sensitivity, selectivity, response kinetics and reliability [4]. The design of active materials is essential and it must be the starting point for the control of the functional parameters of the final device. Nonetheless, great attention must be paid to the integration of the active material onto the transducer. In order to have a stable chemical sensor, not only the active material, but all the components of the device, such as electrical contacts and heating system, must be stable and reliable.

The scope of this manuscript is to present different techniques for the preparation of nanostructures, and to show the different sensing capabilities of oxides within a real application, using sensors arrays and electronic noses. Evaporation, thermal oxidation and hydrothermal methods were optimized for the direct integration of metal oxide nanowires into chemical sensor transducers, without using any transfer method that may not guarantee the stability and reproducibility required for potential commercial devices. The deposition has been directly performed on the functional substrates, avoiding post-processing transfer techniques that may decrease the adhesion and therefore the mechanical and electrical stability of the final devices.

In order to prepare an array of sensors, different metal oxides have been studied, both conventional and new ones. We have investigated different preparation techniques and materials and we have compared their sensing properties towards two wellknown and studied species (an oxidizing and a reducing gas interesting for environmental monitoring). Moreover, we have integrated metal oxide nanowires into an electronic nose and proved its ability in a real case study, more specifically the detection of water contamination.

\section{Results and Discussion \\ Preparation of metal oxide nanostructures Evaporation-condensation technique: $\mathrm{NiO}, \mathrm{SnO}_{2}$ and $\mathrm{ZnO}$}

Evaporation-condensation allows one to obtain disordered mats of nanowires, covering the area of substrates with the catalyst. Figure 1 (top) shows the FE-SEM images of $\mathrm{NiO}$ nanowires at different magnifications, while Figure 1 (middle) and Figure 1

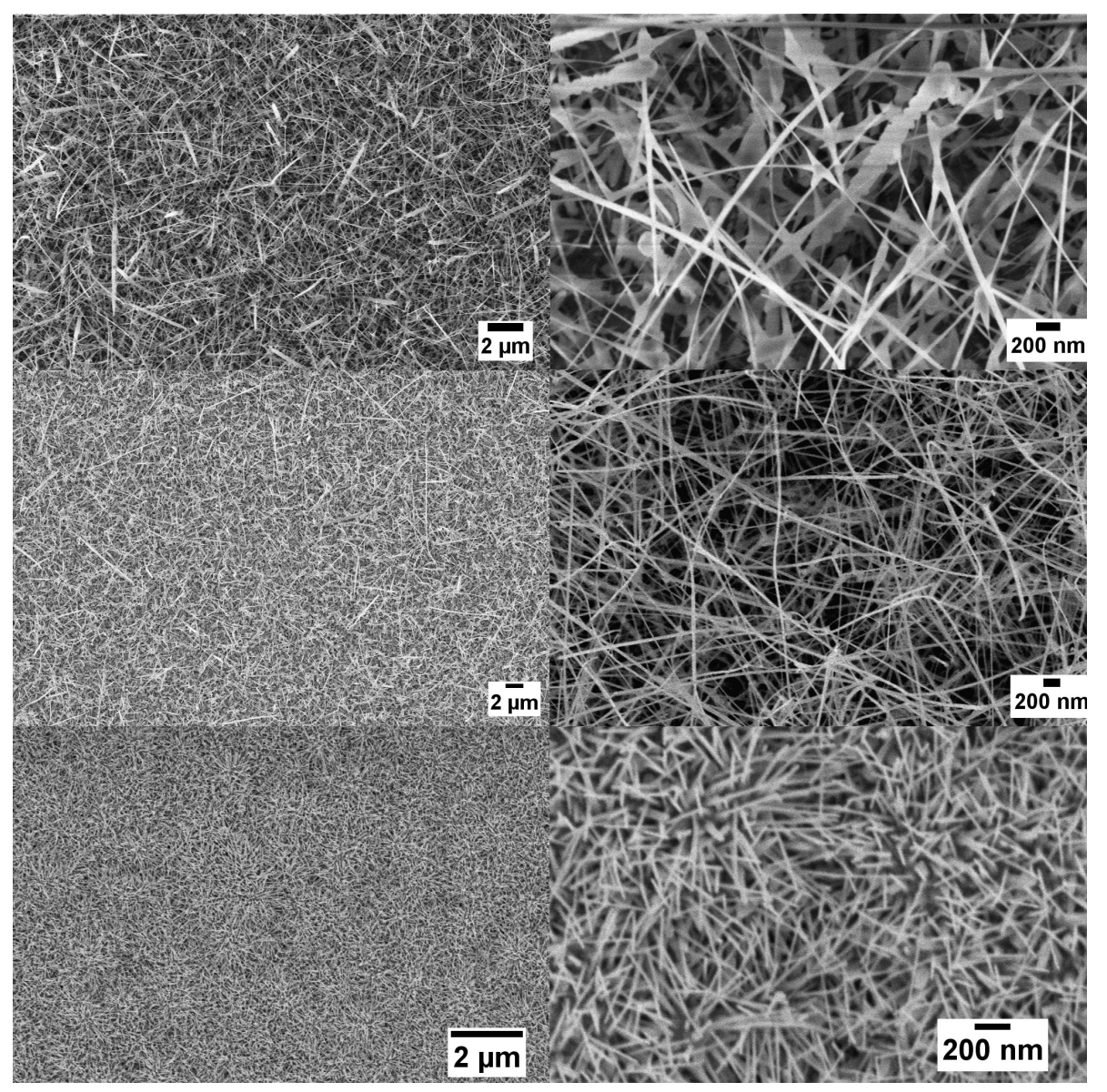

Figure 1: FE-SEM images of $\mathrm{NiO}$ nanowires at different magnifications (top), $\mathrm{SnO}_{2}$ nanowires (middle) and $\mathrm{ZnO}$ nanowires (bottom). 
(bottom) report $\mathrm{SnO}_{2}$ nanowires and $\mathrm{ZnO}$ nanowires, respectively. Nanowires were directly grown on the active substrates used for functional characterization. It has been observed that the $\mathrm{NiO}$ nanowires were grown thin and long and they showed a dense morphology covering the whole substrate. The diameters of these nanowires were found to lie in the range of 20 to $60 \mathrm{~nm}$. The same holds for tin oxide nanowires, even if in this case nanowires are distributed more uniformly on the substrates. $\mathrm{ZnO}$ nanowires exhibit a smaller average diameter $(20-50 \mathrm{~nm})$, but they are also shorter and form a very dense mat.

Raman spectrum of $\mathrm{NiO}$ nanowires (Figure 2) shows several bands above $400 \mathrm{~cm}^{-1}$. The first four bands at $584 \mathrm{~cm}^{-1}$, $740 \mathrm{~cm}^{-1}, 903 \mathrm{~cm}^{-1}$ and $1100 \mathrm{~cm}^{-1}$ have vibrational origin. The first band at $584 \mathrm{~cm}^{-1}$ corresponds to one phonon TO (transverse mode) and LO (longitudinal mode), $740 \mathrm{~cm}^{-1}$ to the two phonon $2 \mathrm{TO}$ modes, $903 \mathrm{~cm}^{-1}$ to the TO+LO and $1100 \mathrm{~cm}^{-1}$ is related to the $2 \mathrm{LO}$ modes. One last strong band was observed at $1482 \mathrm{~cm}^{-1}$ and it belongs to magnon (2M) scattering [5]. The extra peak that appears in the spectra below $450 \mathrm{~cm}^{-1}$ belongs to the alumina substrate.

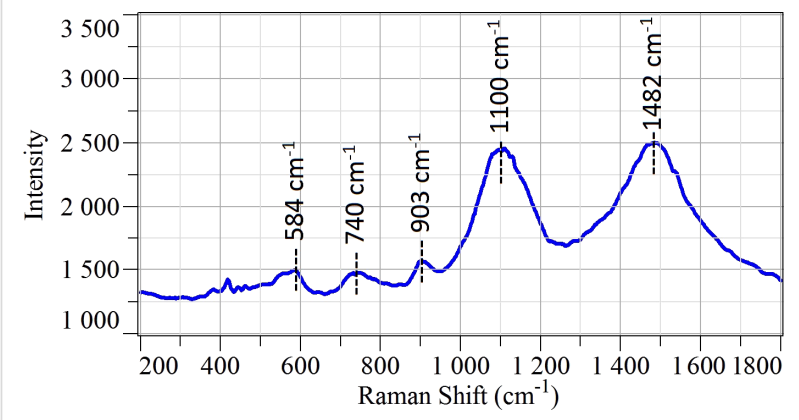

Figure 2: Raman spectrum of $\mathrm{NiO}$ nanowires deposited on alumina substrate measured in ambient air at room temperature.

Concerning $\mathrm{SnO}_{2}$, three major peaks are detected in the Raman spectrum in Figure 3. The peaks located at 489, 624 and $764 \mathrm{~cm}^{-1}$ are related to $\mathrm{E}_{\mathrm{g}}, \mathrm{A}_{1 \mathrm{~g}}$ and $\mathrm{B}_{2 \mathrm{~g}}$ vibration modes, respectively. These peaks are the common Raman peaks of tetragonal rutile bulk $\mathrm{SnO}_{2}$, as reported in literature [6].

The $\mathrm{ZnO}$ Raman spectrum is reported in Figure 4. Typical modes for $\mathrm{ZnO}$ crystals are a longitudinal optical (LO) mode, measured at $584 \mathrm{~cm}^{-1}$, and the transverse $\mathrm{A}_{1}$ mode, measured at $380 \mathrm{~cm}^{-1}$. Moreover, there are one $\mathrm{E}_{2}$ vibration at $433 \mathrm{~cm}^{-1}$ and one transverse (TO) mode $\mathrm{E}_{1}$ at about $400 \mathrm{~cm}^{-1}$, which is contributing to the tail of the $\mathrm{E}_{2}$ peak. The signal at $331 \mathrm{~cm}^{-1}$ is a second-order vibration.

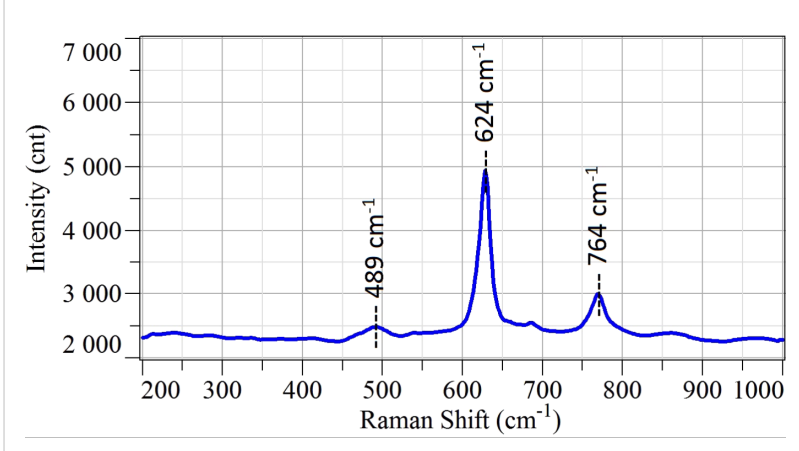

Figure 3: Raman spectrum of $\mathrm{SnO}_{2}$ nanowires deposited on alumina substrate measured in ambient air at room temperature.

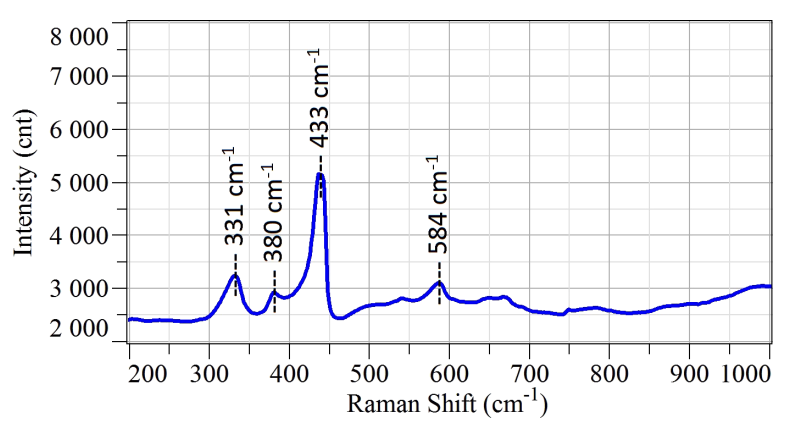

Figure 4: Raman spectrum of $\mathrm{ZnO}$ nanowires deposited on alumina substrates measured in ambient air at room temperature.

\section{Thermal oxidation technique: $\mathrm{WO}_{3}$}

Thermal oxidation of metallic tungsten films resulted in a disordered mats of tungsten oxide nanowires, covering all the patterned area of the substrates. Figure 5 reports a SEM picture of the nanowires, at 50k magnification, highlighting the lack of a preferred orientation on the substrate. The average diameter of the nanowires is very small $(20-30 \mathrm{~nm})$ while the length is approximately $1-2 \mu \mathrm{m}$.

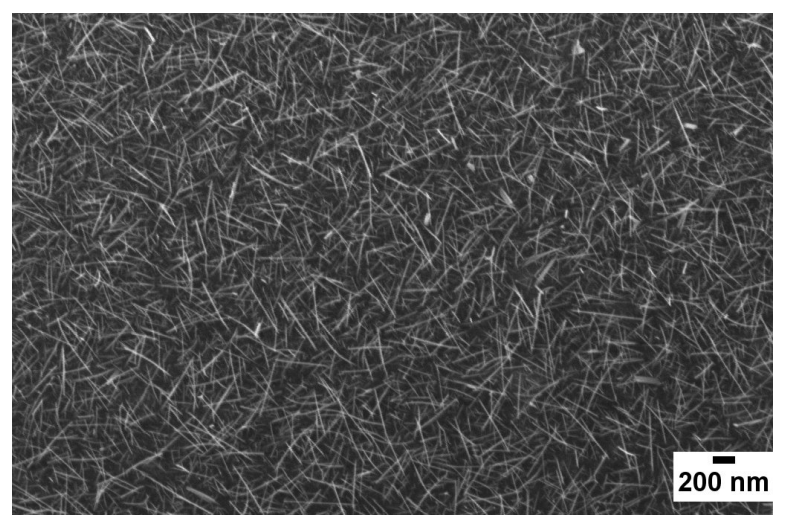

Figure 5: SEM picture of $\mathrm{WO}_{3}$ nanowires on alumina substrate. 
Raman spectroscopy was performed on the samples to evaluate the crystallinity and the composition of the material. Figure 6 reports the Raman spectrum of $\mathrm{WO}_{3}$ nanowire networks. All identified peaks can be attributed to tungsten trioxide, while there is no sign of alumina (corundum) peaks related to the polycrystalline substrate. This means that tungsten oxide covers the entire substrates. More specifically, the peaks at $707 \mathrm{~cm}^{-1}$ and $797 \mathrm{~cm}^{-1}$ are related to the stretching vibration of bridging oxygen in (W-O-W) bonds [7], and they are typical peaks of monoclinic tungsten trioxide. The other two major peaks at $262 \mathrm{~cm}^{-1}$ and $322 \mathrm{~cm}^{-1}$ are due to the bending vibration of (O-W-O) bonds [8].

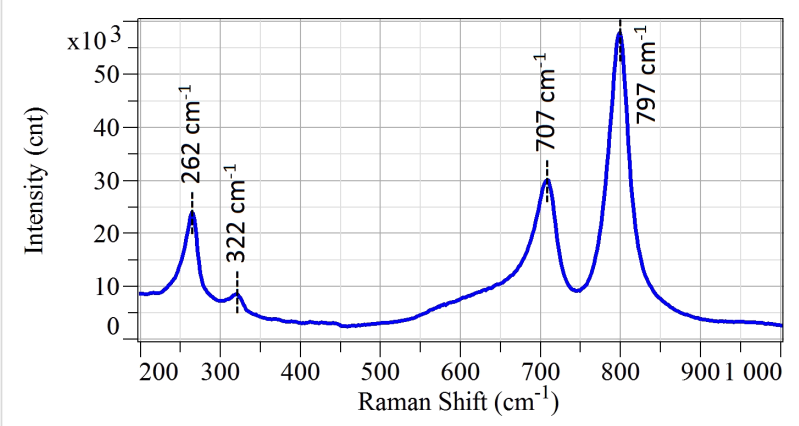

Figure 6: Raman spectrum performed on $\mathrm{WO}_{3}$ nanowire deposited on alumina substrate measured in ambient air at room temperature.

\section{Hydrothermal technique: $\mathrm{Nb}_{2} \mathrm{O}_{5}$}

During the preparation of niobium oxide nanostructures using a hydrothermal technique, during the first experiments we had adhesion problems of the metal layer to the substrates. We changed the thickness of the film, working temperature, $\mathrm{KOH}$ molarity and time in order to find out the best conditions to synthetize niobium oxide nanostructures directly onto the substrate. Once we achieved reproducible results, nanostructures were investigated in terms of morphology, structural features and functional properties. By using scanning electron microscopy (SEM, LEO 1525) it was possible to verify the presence of the nanostructures on alumina substrates and show their morphology. During the hydrothermal treatment $\mathrm{Nb}_{2} \mathrm{O}_{5}$ nanoflowers were formed (Figure 7).

Raman spectroscopy was performed in order to scrutinize the structural properties of the material. The analysis showed the presence of niobium oxide with residual potassium from the use of $\mathrm{KOH}$ during the hydrothermal treatment (Figure 8).

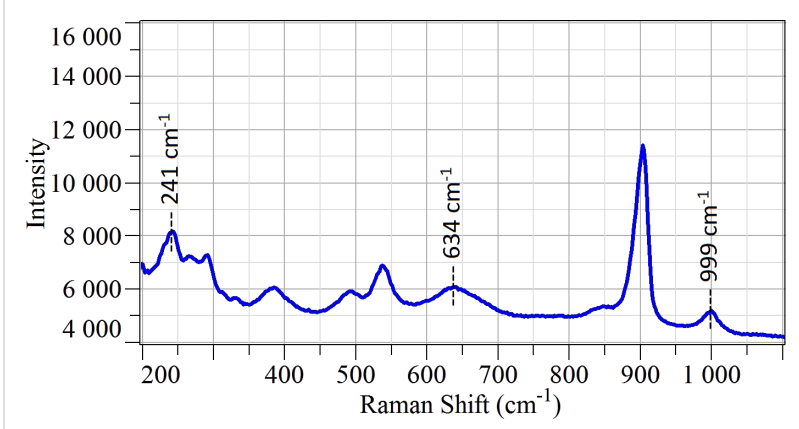

Figure 8: Raman spectrum of $\mathrm{Nb}_{2} \mathrm{O}_{5}$ nanoflowers deposited on alumina substrate measured in ambient air at room temperature.

The niobium(V) oxide peaks in Figure 8 (marked by dashed lines) match the ones reported in literature $[9,10]$. The peak at $999 \mathrm{~cm}^{-1}$ corresponds to longitudinal optical mode (LO) of $\mathrm{Nb}-\mathrm{O}$ stretching associated to $\mathrm{NbO}_{6}$ octahedra. The corresponding transverse optical (TO) mode is observed at $634 \mathrm{~cm}^{-1}$. The band close to $241 \mathrm{~cm}^{-1}$ is related to $\mathrm{Nb}-\mathrm{O}-\mathrm{Nb}$ bending [10]. The remaining peaks are related to residual potassium, which forms a $\mathrm{K}_{x} \mathrm{Nb}_{y} \mathrm{O}_{z}$ ternary compound, specifically $\mathrm{K}_{4} \mathrm{Nb}_{6} \mathrm{O}_{17}$ [11]. Due to the growth technique used, it is very difficult to separate the contribution of pure $\mathrm{Nb}_{2} \mathrm{O}_{5}$ from $\mathrm{K}_{4} \mathrm{Nb}_{6} \mathrm{O}_{17}$. In literature, there are no reports on the sensing per-

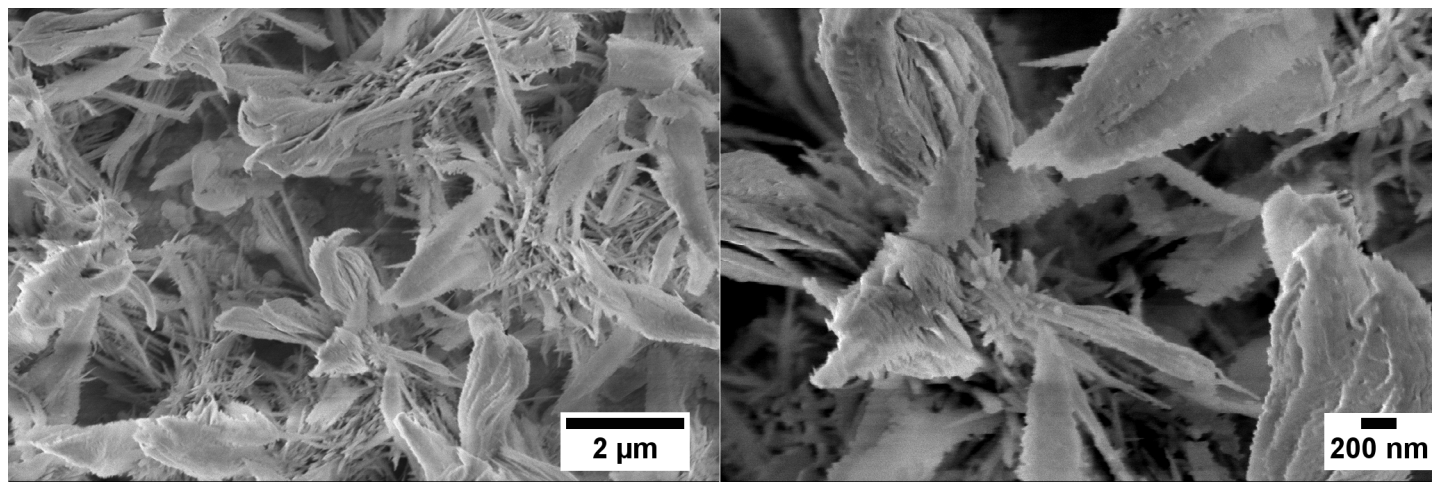

Figure 7: SEM images of $\mathrm{Nb}_{2} \mathrm{O}_{5}$ nanoflowers at $25 \mathrm{k}$ (left) and $75 \mathrm{k}$ (right) magnification level. 
formance of this ternary compound as chemical sensor. However, it is a promising material for water splitting applications $[12,13]$.

\section{Functional tests}

After morphological and structural analysis, we investigated the functional properties of these active materials as chemical sensors. In general, when a metal oxide such as $\mathrm{SnO}_{2}$ is exposed to dry air [14,15], there is adsorption of oxygen molecules on the surface, leading to the formation of active oxygen species such as $\mathrm{O}^{-}, \mathrm{O}^{2-}$ and $\mathrm{O}_{2}^{-}$. These adsorbed ions trap free electrons from the surface, thus changing the overall electrical conductance of the material. When we release a reducing gas species in the atmosphere, gas molecules interact with these pre-adsorbed oxygen ions releasing electrons on the surface of the material. This injection of free carriers results in an increase (for n-type semiconductors) or decrease (for p-type semiconductors) of the electrical conductance, respectively. For example, if we consider $\mathrm{CO}$ as target species to be detected we have (Equation 1) [14]:

$$
\mathrm{CO}_{(\mathrm{g})}+\mathrm{O}_{(\text {ads })}^{-} f \mathrm{CO}_{2(\mathrm{~g})}+\mathrm{e}^{-}
$$

In the presence of oxidizing species such as $\mathrm{NO}_{2}$, the interaction on the oxide surface leads to an increase of the number of adsorbed species from the gas phase. This results in an increase of electrical conductance for for p-type materials and, correspondingly, a decrease for n-type materials. This behaviour can be better explained through the following reactions in dry air [15]:

$$
\begin{gathered}
\mathrm{NO}_{2(\mathrm{~g})}+\mathrm{e}^{-} € \mathrm{NO}_{2}^{-}(\text {ads }) \\
\mathrm{NO}_{2(\mathrm{~g})}+\mathrm{e}^{-} € \mathrm{NO}_{(\mathrm{g})}+\mathrm{O}^{-}
\end{gathered}
$$

The role of water vapour also needs to be taken into account [16-18], but its effect on the sensing mechanism strongly depends on the used material. For example, it has been demonstrated that for $\mathrm{SnO}_{2}$, humidity competes with reducing gases for the same reactive oxygen species, and it has a site blocking effect when interacting with the surface $[16,17]$. For this reason, in presence of humidity the concentration of adsorbed oxygen is lower, and the response of the $\mathrm{SnO}_{2}$ sensor to $\mathrm{CO}$ is lower than under dry conditions. On the contrary, the lattice of $\mathrm{WO}_{3}$ is oxidized by humidity, and more reaction sites for $\mathrm{CO}$ are present on the surface than in dry air [18].

As an example, we report in Figure 9 the dynamic response of $\mathrm{NiO}$ (p-type) and $\mathrm{Nb}_{2} \mathrm{O}_{5}$ (n-type) devices. In the presence of reducing $\mathrm{CO}$ we observed a decrease in electrical conductance for $\mathrm{NiO}$ sensor and an increase in case of $\mathrm{Nb}_{2} \mathrm{O}_{5}$.

Theoretical calculations have shown that the response of p-type metal oxide semiconductors toward a specific target compound should be equal to the square root of that of an n-type metal oxide semiconductor under the same conditions (morphology, structure). This is due to the intrinsic nature of the charge carriers of p-type materials (holes) compared to those of n-type materials (electrons) $[19,20]$. However, this does not take into account the specific catalytic properties of each material. For some applications p-type materials could perform better than n-type materials.

Moreover, the response of a metal oxide gas sensor is influenced also by the morphology, and specifically by the size of the nanostructures [21]. In this work, we investigate the preparation of low-dimensional metal oxide nanowires. However, because of the growth process used and the nature of the materials themselves, it is difficult to have exactly the same nanostructures for all five different materials and, therefore, a direct comparison is difficult. It is a very complex task to desribe the sensing mechanism of each semiconducting metal oxide. It
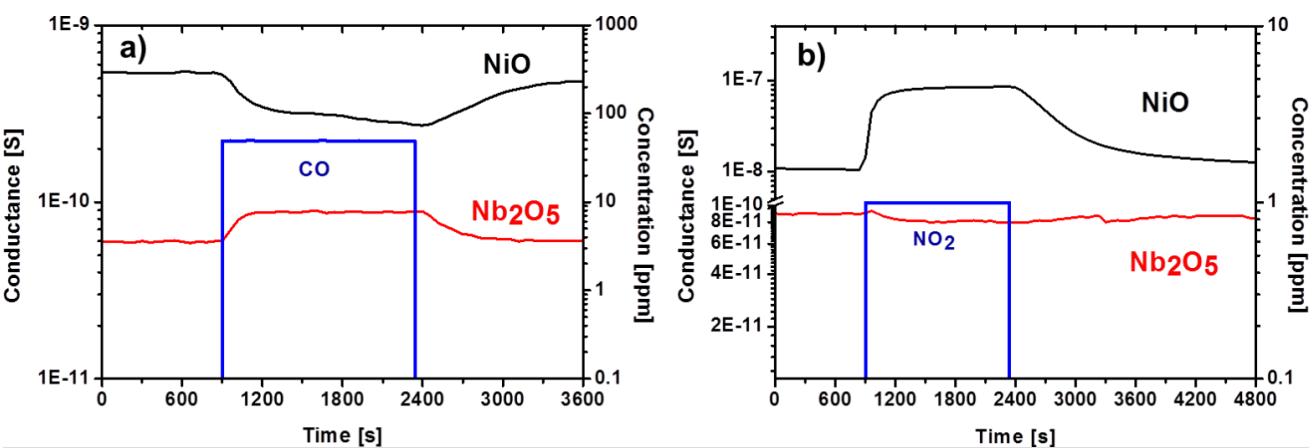

Figure 9: Dynamic response of $\mathrm{NiO}$ and $\mathrm{Nb}_{2} \mathrm{O}_{5}$ sensing devices towards (a) $\left(\mathrm{CO} ; 50 \mathrm{ppm}, \mathrm{NiO}\left(300{ }^{\circ} \mathrm{C}\right)\right.$ and $\left.\mathrm{Nb}_{2} \mathrm{O}_{5}\left(400{ }^{\circ} \mathrm{C}\right)\right)$ and $(\mathrm{b})\left(\mathrm{NO}_{2} ; 1 \mathrm{ppm}\right.$ $\mathrm{NiO}\left(200^{\circ} \mathrm{C}\right)$ and $\mathrm{Nb}_{2} \mathrm{O}_{5}\left(400^{\circ} \mathrm{C}\right)$ ) measured at a relative humidity of $50 \%$ at $20^{\circ} \mathrm{C}$ 
requires a comprehensive characterization of the materials together with a deep understanding of the surface reactions. Operando measurements, in which electrical measurements and spectroscopic investigations are performed simultaneously on the material, have proven to be a powerful investigation tool in answering some questions about the sensing mechanism $[22,23]$.

In the present manuscript, we report the sensing performance of five different nanostructured metal oxides, synthetized directly on the transducers used to fabricate the final device. A temperature screening was performed in order to identify the optimal working temperature of each material in the detection of the two target chemical compounds. Results are reported in Figure 10. As expected, each material behaves differently, and the working temperature has a strong effect on the response. Although some materials are more suited than others to detect $\mathrm{CO}$ or $\mathrm{NO}_{2}$, it is important to mention that all metal oxides exhibit cross-sensitivity to other chemical species too. This lack of selectivity toward specific chemical species is one of the major drawbacks of the conductometric use of metal oxides. However, an array of devices based on different materials, each with its own sensing properties (a so-called electronic nose), could provide a robust and versatile tool for the unambiguous detection of volatile compounds.

Considering carbon monoxide as target gas, it is evident that $\mathrm{WO}_{3}$ is the most sensitive material, at almost every temperature. The optimal temperature is $200{ }^{\circ} \mathrm{C}$, exhibiting a response of about 4.5 to $50 \mathrm{ppm}$ of $\mathrm{CO}$. The response of other materials is significantly lower, and the optimal working temperature is higher than that of $\mathrm{WO}_{3}$. The excellent performance of $\mathrm{WO}_{3}-$ based devices could be related to the very small dimensions of the nanowires. However, the sensing mechanism of $\mathrm{WO}_{3}$ toward $\mathrm{CO}$ may differ from the one of other metal oxides. In particular, former studies [23] suggest that CO can locally reduce the surface of $\mathrm{WO}_{3}$ nanowires, strongly influencing the electrical conductance of the surface. This is not observed, for example, in sensors based on $\mathrm{SnO}_{2}$ nanowires. Unfortunately, up to now we do not have enough information to determine which parameter has the biggest impact on the sensor response.

Concerning nitrogen dioxide instead, NiO is very sensitive, more than all other materials. The optimal working temperature of $\mathrm{NiO}$ is $200{ }^{\circ} \mathrm{C}$, with a response of about 6 to $1 \mathrm{ppm}$ of $\mathrm{NO}_{2}$. At lower temperatures $\left(100{ }^{\circ} \mathrm{C}\right), \mathrm{NiO}$ devices are too resistive to be measured in our test chamber. $\mathrm{NiO}$ has hardly been studied as a material for chemical sensors. Hence, there are only few reports about a tentative $\mathrm{NO}_{2}$ sensing mechanism. Zhang et. al. [24] pointed out that nickel vacancies could play an important role in the interaction between $\mathrm{NO}_{2}$ and the $\mathrm{NiO}$ surface and in the sensing mechanism in general.

The calibration curves reported in Figure 11 exhibit results similar to those of the temperature screening. $\mathrm{WO}_{3}$ is the best-performing material for the detection of $\mathrm{CO}$, at concentrations higher than $10 \mathrm{ppm}$. At lower concentrations, tin-oxide-based devices exhibit a higher response, according to the preliminary calibration curve estimated from the measurement by powerlaw fitting. If the devices are used for the evaluation of air quality in closed spaces [25], it may be necessary to detect concentrations of carbon monoxide lower than $10 \mathrm{ppm}$. Therefore tin-oxide-based devices are ideal candidates.

On the contrary, $\mathrm{NiO}$ performs much better than other oxides for $\mathrm{NO}_{2}$ detection, especially at low concentrations (below $10 \mathrm{ppm}$ ). European Union (EU) Air quality Standards require the average concentration of $\mathrm{NO}_{2}$, in a period of one hour, to be lower than $0.1 \mathrm{ppm}$ [25]. The response of NiO-based devices is sufficiently high to easily detect such concentrations, exhibiting a response of one at $0.1 \mathrm{ppm}$. At higher concentrations (above $10 \mathrm{ppm}$ ), $\mathrm{WO}_{3}$ could be a better choice for the detection
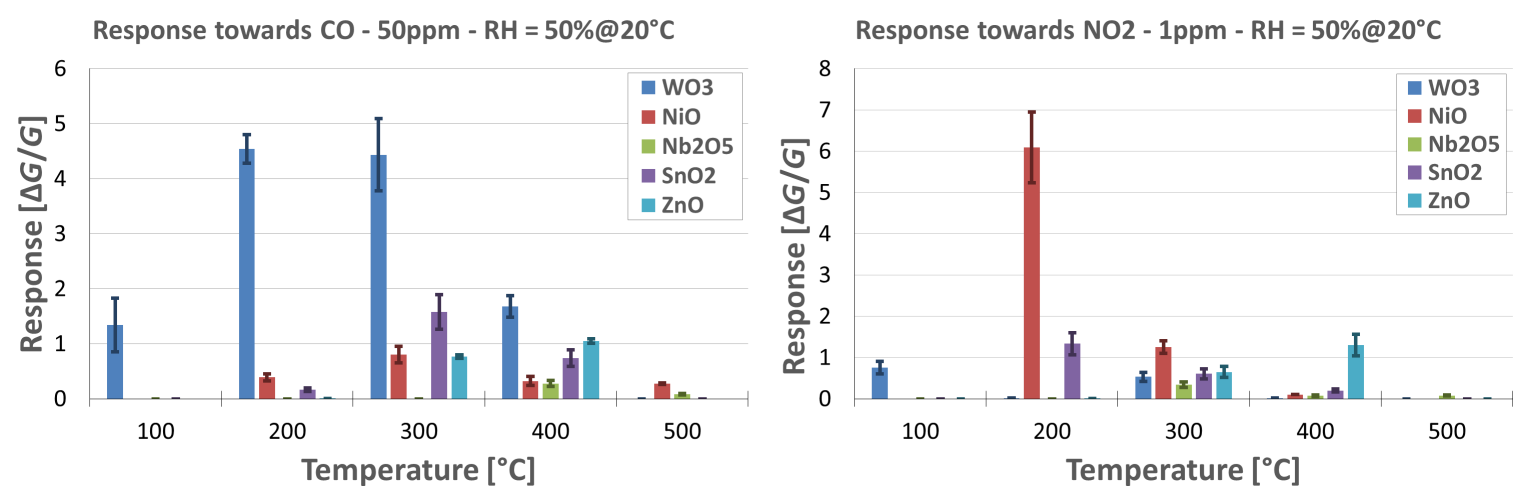

Figure 10: Sensor response towards $50 \mathrm{ppm}$ of $\mathrm{CO}$ (left) and $1 \mathrm{ppm}$ of $\mathrm{NO}_{2}$ (right) as a function of the temperature. The relative humidity was kept constant at $50 \%$, the temperature was $20^{\circ} \mathrm{C}$. 


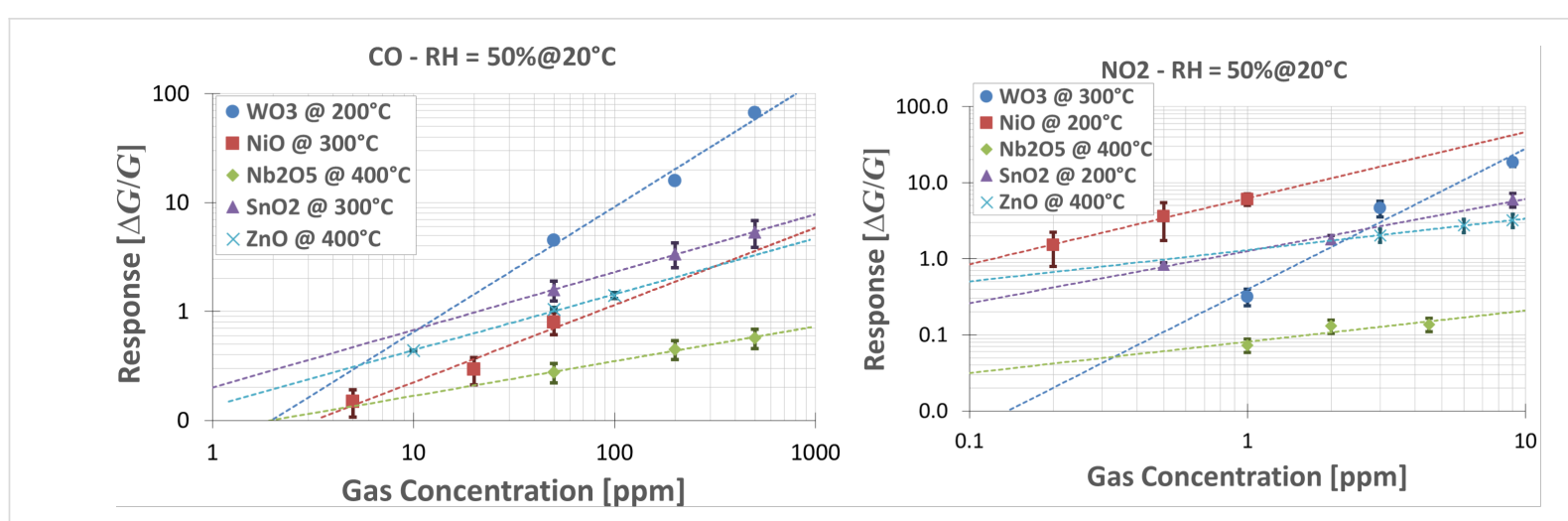

Figure 11: Calibration curves and power-law fitting for $\mathrm{CO}$ (left) and $\mathrm{NO}_{2}$ (right). The relative humidity was kept constant at $50 \%$, the temperature was $20^{\circ} \mathrm{C}$.

of nitrogen dioxide, according to the raw estimation from the power-law fitting. However, such high concentrations are not interesting for environmental monitoring, being far above the air quality requirements [25].

Considering both target gases, $\mathrm{Nb}_{2} \mathrm{O}_{5}$-based sensors exhibit the lowest performance. One explanation could be the higher dimensionality (3D) of these nanostructures compared to nanowires (1D), originating from the aggregation of $1 \mathrm{D}$ or $2 \mathrm{D}$ objects (such as nanowires, nanorods, nanosheets) occurring during the growth [26]. In particular, nanowires exhibit a very high surface-to-volume ratio, and have a large surface area, while the performance of the $\mathrm{Nb}_{2} \mathrm{O}_{5}$ nanoflowers depends on the size of the nanostructures and how they aggregate to the 3D structure. If the assembly leads a low surface-to-volume ratio, the final performance could be degraded.

Reproducibility was also taken into account. For the same material, a batch of different devices was fabricated and measured. In Figure 10 and Figure 11, the average values of these measurements are reported. The variation of the response of an individual sensor is around 5\%. However, in case of sensors produced in different batches it may increase up to $20 \%$. The stability of the devices over medium-term operation was very good. The measurements were not performed sequentially and each sensor was measured over a time of more than two months. Within this interval, sensors continued to work properly, without any significant breakout or loss of performance.

The proposed chemical sensing devices, based on nanostructured materials, were compared to current state-of-the-art devices. Literature data of the performance toward $\mathrm{CO}$ and $\mathrm{NO}_{2}$ of some similar nanostructures were collected in Table 1 . Unfortunately, it was not always possible to find similar gas concentrations, especially for $\mathrm{Nb}_{2} \mathrm{O}_{5}$. This material has hardly been studied in chemical sensors. Therefore, there are not many reports on its sensing performance. Comparing the most responsive materials to $\mathrm{CO}$ and $\mathrm{NO}_{2}\left(\mathrm{WO}_{3}\right.$ and $\mathrm{NiO}$, respectively) with the current state of the art, the presented nanostructures outperform the results reported in literature with similar morphologies.

\section{"Small sensor system" tests}

In order to study these materials in real applications, metal oxide nanowires have been integrated in an electronic nose called "Small Sensor System" (S3). Nanowire devices were integrated together with conventional thin film counterparts, to see if the discerning ability of the electronic nose is affected by the integration of nanostructured active materials. In particular, we decided to integrate tin dioxide and zinc oxide devices, since these are the most widely used and studied materials for chemical sensors.

As a case study, we have chosen the analysis of water contamination. Nowadays, a fast and economic device for the early detection of microbial contamination and quality assurance is needed to reduce the number of food-borne related hospitalizations by year. Moreover, there is a strong need for a portable user-friendly device with low power consumption. Our analysis was performed to verify whether S3 is able to distinguish between drinking and contaminated water. The concentration of pathogenic microorganisms in the contaminated sample is $500 \mathrm{CFU} / \mathrm{mL}$ (CFU = colony-forming units). Pathogenic microorganisms are always used as an indicator of the water quality. In particular, E. coli normally appears at concentrations of 100 to $2 \times 10^{4} \mathrm{CFU} / 100 \mathrm{~mL}$ [49]. In this study, we analysed contaminated water samples in the first $24 \mathrm{~h}$ after sampling. For each contaminated and uncontaminated sample, 40 analyses were performed, for a total of 80 measures. This was necessary to get a substantial statistical ensemble. The principal component analysis (PCA) score plot graph in Figure 12 reports the 
Table 1: Sensing performance reported in literature for some similar metal oxide nanostructures toward $\mathrm{CO}$ and $\mathrm{NO}_{2}$.

\begin{tabular}{|c|c|c|c|c|c|}
\hline structure & method & gas/concentration & response & $\begin{array}{l}\text { transfer of } \\
\text { nanostructures }\end{array}$ & ref. \\
\hline \multicolumn{6}{|c|}{ nickel oxide } \\
\hline $\mathrm{NiO}$ thin film & sol-gel and spin coating & $\mathrm{NO}_{2} / 200 \mathrm{ppm}$ & 0.233@200 ㄷ & no & [27] \\
\hline $\mathrm{NiO}$ nanosheets & hydrothermal method & $\mathrm{NO}_{2} / 20 \mathrm{ppm}$ & $0.8 \% @ 250$ C & yes & {$[28]$} \\
\hline $\mathrm{NiO}$ thin film & $\begin{array}{l}\text { DC reactive magnetron } \\
\text { sputtering }\end{array}$ & $\mathrm{NO}_{2} / 5 \mathrm{ppm}$ & $2.6 @ 160$ C & no & {$[29]$} \\
\hline $\mathrm{NiO}$ nanostructures & hydrothermal reflux process & $\mathrm{CO} / 100 \mathrm{ppm}$ & $1.14 @ 100$ ×C & yes & {$[30]$} \\
\hline $\mathrm{NiO}$ thin film & $\begin{array}{l}\text { DC reactive magnetron } \\
\text { sputtering }\end{array}$ & $\mathrm{CO} / 200 \mathrm{ppm}$ & $0.3 @ 420{ }^{\circ} \mathrm{C}$ & no & [31] \\
\hline
\end{tabular}

\begin{tabular}{|c|c|c|c|c|c|}
\hline \multicolumn{6}{|c|}{ tungsten oxide } \\
\hline $\mathrm{WO}_{3}$ porous thin film & $\begin{array}{l}\text { DC magnetron sputtering } \\
\text { and anodic oxidation }\end{array}$ & $\begin{array}{l}\mathrm{NO}_{2} / 1 \mathrm{ppm} \\
\mathrm{NO}_{2} / 5 \mathrm{ppm}\end{array}$ & $\begin{array}{l}40 @ 150{ }^{\circ} \mathrm{C} \\
\text { ca. } 100 @ 150{ }^{\circ} \mathrm{C}\end{array}$ & no & [32] \\
\hline $\mathrm{WO}_{3}$ nanowires & vapor transport method & $\begin{array}{l}\mathrm{NO}_{2} / 5 \mathrm{ppm} \\
\mathrm{CO} / 200 \mathrm{ppm}\end{array}$ & $\begin{array}{l}7.8 @ 200 \text { C } \\
1.4 @ 200 \text { C }\end{array}$ & yes & [33] \\
\hline $\mathrm{WO}_{3}$ nanowires & thermal evaporation & $\begin{array}{l}\mathrm{NO}_{2} / 10 \mathrm{ppm} \\
\mathrm{CO} / 100 \mathrm{ppm}\end{array}$ & $\begin{array}{l}146 @ 250{ }^{\circ} \mathrm{C} \\
1.3 @ 250{ }^{\circ} \mathrm{C}\end{array}$ & no & {$[34]$} \\
\hline $\mathrm{WO}_{3}$ nanorods & thermal evaporation & $\mathrm{CO} / 30 \mathrm{ppm}$ & $\begin{array}{l}0.023 @ 300{ }^{\circ} \mathrm{C} \\
\left(\text { bare } \mathrm{WO}_{3}\right) \\
0.0482 @ 300{ }^{\circ} \mathrm{C} \\
\left(\mathrm{Pt}-\mathrm{WO}_{3}\right)\end{array}$ & yes & {$[35]$} \\
\hline \multicolumn{6}{|c|}{ zinc oxide } \\
\hline $\mathrm{ZnO}$ nanocrystalline thin film & spray pyrolysis & $\mathrm{NO}_{2} / 7 \mathrm{ppm}$ & $3.32 @ 200$ C & yes & {$[36]$} \\
\hline ZnO nanopyramids & non-aqueous route & $\mathrm{NO}_{2} / 10 \mathrm{ppm}$ & 14.5@200C & yes & [37] \\
\hline $\begin{array}{l}\mathrm{ZnO} \text { cacti-like structures }(\mathrm{Zcc}) \& \\
\text { nanoneedles }(\mathrm{Znn})\end{array}$ & chemical route & $\mathrm{NO}_{2} / 200 \mathrm{ppm}$ & $\begin{array}{l}0.89 @ 200{ }^{\circ} \mathrm{C}(\mathrm{Zcc}) \\
0.64 @ 200{ }^{\circ} \mathrm{C}(\mathrm{Znn})\end{array}$ & no & {$[38]$} \\
\hline $\mathrm{ZnO}$ nanocrystalline nanowires & thermal evaporation & $\mathrm{CO} / 1000 \mathrm{ppm}$ & $51.64 @ 300$ C & yes & [39] \\
\hline ZnO nanorod array & hydrothermal route & $\mathrm{CO} / 200 \mathrm{ppm}$ & $2.2 @ 250$ C & no & {$[40]$} \\
\hline \multicolumn{6}{|c|}{ tin oxide } \\
\hline $\mathrm{SnO}_{2}$ thin film & sol-gel and spin coating & $\mathrm{NO}_{2} / 100 \mathrm{ppm}$ & $0.019 @ 200$ C & yes & {$[41]$} \\
\hline $\mathrm{SnO}_{2}$ nanoribbons & thermal deposition process & $\mathrm{NO}_{2} / 3 \mathrm{ppm}$ & 1.16@rt & yes & [42] \\
\hline $\mathrm{SnO}_{2}$ hollow spheres & solution phase deposition & $\begin{array}{l}\mathrm{NO}_{2} / 5 \mathrm{ppm} \\
\mathrm{NO}_{2} / 20 \mathrm{ppm} \\
\mathrm{NO}_{2} / 50 \mathrm{ppm} \\
\mathrm{NO}_{2} / 100 \mathrm{ppm}\end{array}$ & $\begin{array}{l}1150 @ 160{ }^{\circ} \mathrm{C} \\
2031 @ 160{ }^{\circ} \mathrm{C} \\
2471 @ 160{ }^{\circ} \mathrm{C} \\
2229 @ 160{ }^{\circ} \mathrm{C}\end{array}$ & yes & [43] \\
\hline $\mathrm{SnO}_{2}$ nanowires & thermal evaporation & $\mathrm{CO} / 100 \mathrm{ppm}$ & $2.9 @ 400$ C & no & {$[44]$} \\
\hline $\mathrm{SnO}_{2}$ thin film & $\begin{array}{l}\text { hydrothermally treated sol } \\
\text { solution }\end{array}$ & $\mathrm{CO} / 800 \mathrm{ppm}$ & $\begin{array}{l}489.6 @ 350 \text { C } \\
52.4 @ 200{ }^{\circ} \mathrm{C}\end{array}$ & yes & [45] \\
\hline \multicolumn{6}{|c|}{ niobium oxide } \\
\hline $\mathrm{Nb}_{2} \mathrm{O}_{5}$ nanowires & thermal oxidation process & $\mathrm{CO} / 200 \mathrm{ppm}$ & ca.0.1@rt & no & {$[46]$} \\
\hline $\mathrm{Nb}_{2} \mathrm{O}_{5}$ thin film & RF sputtering & $\mathrm{CO} / 50 \mathrm{ppm}$ & ca.1.66@350 ㄷ & yes & {$[47]$} \\
\hline $\begin{array}{l}\text { monodispersed } \mathrm{Nb}_{2} \mathrm{O}_{5} \\
\text { microspheres }\end{array}$ & solvothermal route & $\mathrm{NO}_{2} / 5 \mathrm{ppm}$ & ca. 2@450C & yes & [48] \\
\hline
\end{tabular}

data corresponding to contaminated and uncontaminated water. It is evident that the measurements of these two samples are well separated into two different clusters. Therefore, the analysis is able to distinguish between contaminated water and drinking water.
$\mathrm{SnO}_{2}$ nanowires $\mathrm{S} 3$ sensors perform best in terms of response, compared to their thin film counterpart for the class of VOCs analysed. The S3 was able to achieve information about the whole fingerprint emitted from contaminated and uncontaminated water. At the same time the $\mathrm{S} 3$ device is not able to iden- 


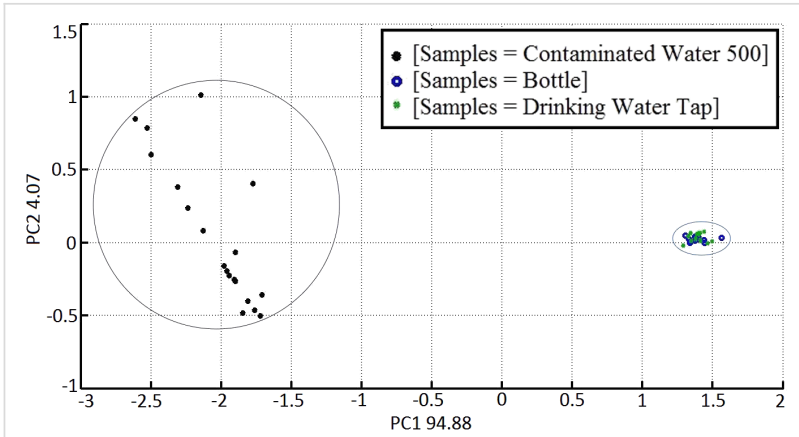

Figure 12: Principal component analysis (PCA) score plot for drinking water (blue and green dots) and a solution with $500 \mathrm{CFU} / \mathrm{mL}$ pathogenic microorganisms (black dots)

tify, without training, a specific VOC. In order to gain more information about the VOCs, analysis with classical chemical techniques such as GC-MS-SPME was carried out simultaneously revealing the most representative compounds related to microbial grow (Table 2).

Table 2: Volatile chemical compounds identified, using SPME-GC-MS in the contaminated water.

\begin{tabular}{ll} 
retention time [min] & compound \\
\hline 1.646 & 2-methylbutene \\
1.726 & 2-methyl-1,3-butadiene \\
2.271 & 4-methyl-2-hexanone \\
2.436 & trans-3,5-methoxycyclohexanone \\
2.453 & acetone \\
3.129 & 5-methyl-2-phenyl-1H-indole \\
6.208 & 2-fluoropropylene \\
10.316 & 5-methyl-2-hexanone \\
10.844 & 1,8-cineol \\
10.969 & pentanol \\
10.975 & 3-methyl-1-butanol \\
11.759 & 2,4-nonadienal \\
13.304 & 2-octanone \\
14.919 & 4-methylpentane \\
14.923 & formic acid methyl ester \\
16.491 & acid 5-alpha-2-cholestanol \\
16.781 & heptanol \\
17.111 & 2,5-dimethylfuran \\
17.440 & 1-octadecylamine \\
17.991 & benzaldehyde \\
18.076 & hexadecanol \\
18.230 & octanol \\
18.690 & dimethyl methylphosphonate \\
19.042 & octane \\
19.105 & \\
19.292 & 4-methylthiazole \\
19.298 &
\end{tabular}

In Figure 13, the content of five volatile organic compounds (VOCs) in the sample with contaminated water is given over a period of seven days. T0 is the day of inoculation, T1 is the measurement 1 day after inoculation ( 24 hours) and T7 is the measurement 7 days after the inoculation. Acetone, 2-fluoropropylene and 3-methyl-1-butanol are neoformation VOCs, because they were not present at $\mathrm{T} 0$. These compounds formed during microbial growth. Heptanol and octanol were present at $\mathrm{T} 0$ and their concentration increased. There is a defined and individual growth mode for every microorganism correlated with optimal time and temperature, and every step of the microbial growth is associated with a specific VOC.

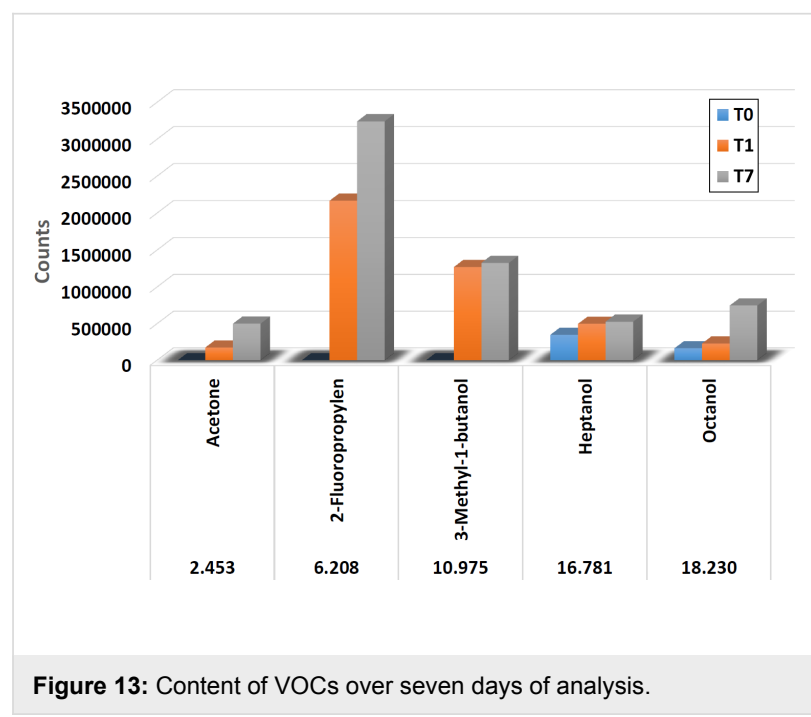

\section{Conclusion}

We have successfully obtained nanostructures, in form of wires or flowers, of the oxides of nickel, tungsten, niobium, zinc and tin. The structures were directly deposited on functional substrates using various techniques and procedures. We have demonstrated that a direct integration with all the three presented deposition techniques is possible, which is an essential feature to commercialize chemical sensors based on these structures.

Surface morphology and composition were studied through scanning electron microscopy and Raman spectroscopy, respectively, confirming the high surface-to-volume ratio (fundamental for chemical sensing). Moreover, we tested the functional properties with respect to chemical sensing. Different batches of sensors have been prepared, and their sensing performances towards carbon monoxide and nitrogen dioxide have been explored. The results show that the best-performing materials for detecting $\mathrm{CO}$ are $\mathrm{WO}_{3}$ and $\mathrm{SnO}_{2}$, while $\mathrm{NiO}$ performs much better than other materials in the detection of $\mathrm{NO}_{2}$, especially at low concentrations. 
To have a clearer concerning realistic applications not only the entire sensing system (the active material plus sensing transducer) but also the entire device integrated into an electronic nose were studied. We have carried out "real-life" tests that confirm the feasibility and clearly demonstrate the potentiality of metal oxide chemical sensors in discriminating among drinking and contaminated water.

\section{Experimental}

\section{Preparation of metal oxide nanostructures}

Alumina substrates $\left(2 \times 2 \mathrm{~mm}^{2}, 99 \%\right.$ purity, Kyocera, Japan $)$ were cleaned in acetone using an ultrasonic cleaner for $15 \mathrm{~min}$ to remove dust and impurities from the substrates. Substrates were dried with pure compressed air. The following techniques were used to grow different metal oxide nanostructures.

\section{Evaporation-condensation technique: $\mathrm{NiO}, \mathrm{SnO}_{2}$, $\mathrm{ZnO}$}

The growth of nickel oxide $(\mathrm{NiO})$, tin dioxide $\left(\mathrm{SnO}_{2}\right)$ and zinc oxide $(\mathrm{ZnO})$ nanowires was performed by evaporation-condensation on alumina substrates [50]. It consists of a controlled evaporation of metal oxide powder followed by a condensation of vapor on a catalyzing substrate. The main parameters to optimize during evaporation-condensation are the evaporation temperature of the source material and the condensation temperature at which materials start to condensate and grow as 1D nanostructure. An ultrathin layer of gold particles were deposited on alumina substrates with RF magnetron sputtering at $70 \mathrm{~W}$, Ar flow $7 \mathrm{sccm}$ for $5 \mathrm{sec}$, acting as a catalyst for the synthesis of nanowires.

Figure 14 shows the basic mechanism of the evaporation-condensation process including three phases of material. At a certain temperature, the formation of a liquid alloy of metal and catalyst starts by absorbing vapors of the source material. As vapors of the source material are continually provided, the material starts to condensate in the form of a solid precipitate. The 1D crystal growth begins, and it continues as long as the source material is supplied [51].

The nanowire growth was carried out in a custom-made tubular furnace [52]. The evaporation temperature of $\mathrm{NiO}$ powder was

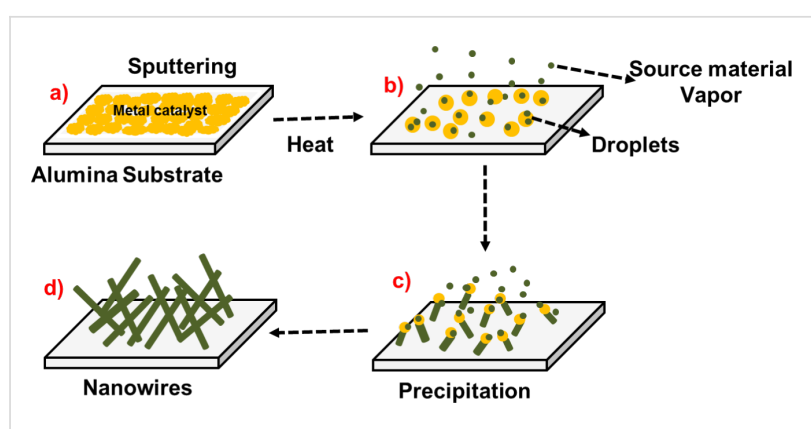

Figure 14: Growth of 1D structures by evaporation-condensation.

set at $1400{ }^{\circ} \mathrm{C}$ and at $1370{ }^{\circ} \mathrm{C}$ for $\mathrm{SnO}_{2}$ and $\mathrm{ZnO}$. Au-deposited substrates were placed at a temperature of $930{ }^{\circ} \mathrm{C}$ inside an alumina tube of the tubular furnace. Argon gas was used as a carrier gas and its flow was set at $100 \mathrm{sccm}$. Furthermore, the pressure of the tube was kept at $1 \mathrm{mbar}$ for $\mathrm{NiO}$ and $100 \mathrm{mbar}$ for $\mathrm{ZnO}$ and $\mathrm{SnO}_{2}$, with a deposition time of $15 \mathrm{~min}$.

\section{Thermal oxidation technique: $\mathrm{WO}_{3}$}

Thermal oxidation is an established technique for the synthesis of copper oxide nanostructures [53]. In this work, we used this technique to synthetize tungsten trioxide $\left(\mathrm{WO}_{3}\right)$ nanowires directly on the final transducer, starting from a metallic tungsten layer deposited by magnetron sputtering [54].

Metallic tungsten was deposited by RF magnetron sputtering $\left(100 \mathrm{~W}, 5 \times 10^{-3} \mathrm{mbar}\right.$, argon plasma, room temperature) via a shadow-mask technique, in order to obtain a $180 \mathrm{~nm}$ thin layer on top of the substrate. Afterwards, the samples underwent a thermal oxidation process in a tubular furnace, in reactive atmosphere. More specifically, the samples were placed in the middle of an alumina tubular furnace at a temperature of $600{ }^{\circ} \mathrm{C}$. A dry pump was used to reach a pressure of $1 \mathrm{mbar}$ inside the tube, and a flow of argon (10 mbar) was injected in the tube through a mass-flow controller (MKS, Germany). The oxidation time was $1 \mathrm{~h}$. Under these conditions, the oxidation process only involves the superficial layer. After thermal oxidation, samples were thermally annealed in air for $12 \mathrm{~h}$ at $500{ }^{\circ} \mathrm{C}$, to completely oxidize the material and remove all the metallic tungsten on the bottom of the nanowires. The schematic workflow to obtain $\mathrm{WO}_{3}$ nanowires is reported in Figure 15.

\begin{tabular}{|ccc|cc}
\hline $\begin{array}{c}\text { Alumina } \\
\text { Substrate }\end{array}$ & $\begin{array}{c}\text { Tungsten } \\
\text { Deposition }\end{array}$ & $\begin{array}{c}\text { Thermal } \\
\text { Annealing }\end{array}$ \\
& $\begin{array}{c}\text { Substrate } \\
\text { Cleaning }\end{array}$ & Thermal & Tungsten \\
Oxide \\
Nanowire
\end{tabular}

Figure 15: Flow chart describing the synthesis process of tungsten oxide nanowires. 


\section{Hydrothermal technique: $\mathrm{Nb}_{2} \mathrm{O}_{5}$}

In the last few years, the hydrothermal technique achieved more and more relevance in crystal growth and in particular the preparation of nanostructures because it can be used for different materials such as metal oxides, carbon nanostructures and biomaterials [55]. In this work, we applied this technique in order to obtain niobium oxide nanostructures. We started from the method explained by Fang et al. [56], but worked on a thin layer of niobium deposited on alumina substrates by magnetron sputtering. For this reason, we carried out several experiments to obtain the optimal conditions (set out below) for the growth of nanostructures. RF magnetron sputtering was used to deposit a metallic niobium film with a thickness of $500 \mathrm{~nm}$ on the substrates. In order to obtain this thickness, niobium was deposited for $41 \mathrm{~min}$ at room temperature, the power applied to the target was set to $100 \mathrm{~W}$, the flow of argon was set to $7 \mathrm{sccm}$ and the chamber pressure was around $5.3 \times 10^{-3} \mathrm{mbar}$.

The obtained samples were placed in a Teflon beaker with a $0.01 \mathrm{M} \mathrm{KOH}$ solution and they were placed in a high-pressure reactor. All the system was heated at $175^{\circ} \mathrm{C}$ for $6 \mathrm{~h}$ and it was cooled down naturally. After this treatment, a white compound was present on the samples surface and an acid treatment was necessary, followed by an annealing step to obtain niobium oxide. For this reason, the prepared samples were treated with $2 \mathrm{M} \mathrm{HNO}_{3}$ solution for $48 \mathrm{~h}$ and then they were annealed at $650{ }^{\circ} \mathrm{C}$ for $6 \mathrm{~h}$. At the end of the process $\mathrm{Nb}_{2} \mathrm{O}_{5}$ nanoflowers were found on the surface of alumina substrates (Figure 16).

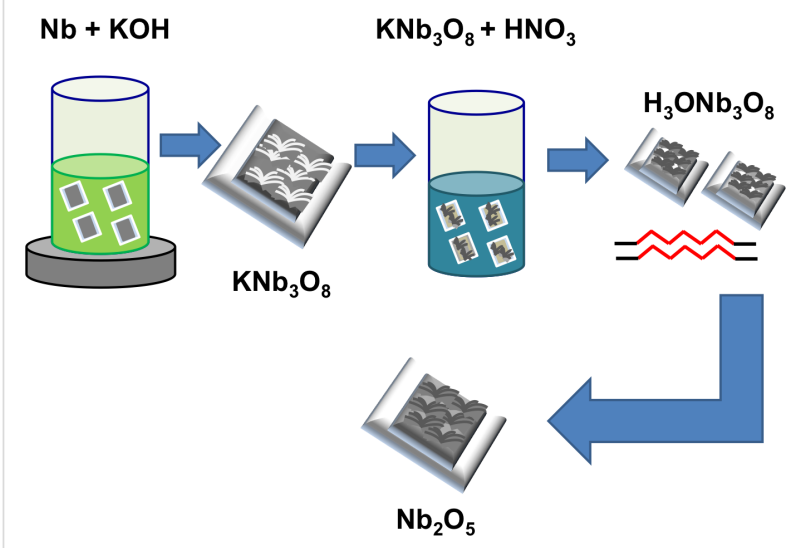

Figure 16: Flow chart describing the synthesis process for niobium oxide nanostructures by hydrothermal treatment.

\section{Characterization techniques}

A field-emission scanning electron microscope (FE-SEM) LEO 1525 was used to investigate the morphology of samples. The electron beam was set at 3-5 keV energy and the samples were attached to metallic stub via carbon glue, to reduce charging effect due to the interaction of electron beam with the specimens.

Raman spectra were measured using a HORIBA monochromator iHR320, with a grating of 1800 grooves $\cdot \mathrm{mm}^{-1}$ and coupled to a Peltier-cooled Synapse CCD (HORIBA). A helium-cadmium (He-Cd) blue laser (442 nm) was focused on the samples by a fiber-coupled confocal optical microscope (HORIBA) at $50 \times$ magnification. Spectra were recorded in the wavelength range of $200-1000 \mathrm{~cm}^{-1}\left(\mathrm{WO}_{3}, \mathrm{SnO}_{2}\right.$ and $\mathrm{ZnO}$ nanowires), 200-1800 $\mathrm{cm}^{-1}$ (NiO nanowires) and $100-1500 \mathrm{~cm}^{-1}\left(\mathrm{Nb}_{2} \mathrm{O}_{5}\right.$ nanostructures $)$.

\section{Functional tests}

Conductometric sensing devices were fabricated to integrate metal oxide nanowires in functional devices. Interdigited platinum electrodes were deposited on top of nanowires by DC magnetron sputtering $\left(70 \mathrm{~W}, 5 \times 10^{-3} \mathrm{mbar}\right.$, argon plasma, room temperature, $1 \mu \mathrm{m}$ thickness). On the back side of the alumina substrates, platinum heating elements were deposited using the same sputtering technique. Samples were finally mounted on TO39 packages using electro-soldered gold wires.

A flow-meter technique was used to evaluate the performance of fabricated conductometric devices for the detection of two common air contaminants, namely carbon monoxide (CO) and nitrogen dioxide $\left(\mathrm{NO}_{2}\right)$. Samples were mounted in a test chamber of $1 \mathrm{~L}$ volume enclosed in a custom-made climatic chamber, set at $20{ }^{\circ} \mathrm{C}$, to remove any influence from external ambient conditions. A fixed voltage of $1 \mathrm{~V}$ was applied to the sensing element of each sensor, while the current flowing was measured by picoamperemeters (Keithley). The temperature of the sensors was controlled independently by applying a known electrical power to the heaters. A temperature screening was performed, to identify the optimal working temperature of the materials. Metal oxide materials may exhibit a small drift in the electrical conductance during the heating process due to the desorption of gases, heat diffusion and mechanical stress. To reduce this effect as much as possible and thus have a stable baseline, we thermally stabilized $(8 \mathrm{~h})$ the samples at a selected target temperature prior to gas-sensing measurements. Different concentrations of target chemical compounds (SIAD, Italy) were injected inside the chamber for $30 \mathrm{~min}$, followed by $1 \mathrm{~h}$ of recovery using synthetic air. The relative humidity was kept constant at $50 \%$.

\section{Small sensor system}

The device we used in this work is a "Small Sensor System" (S3). The sensor array is located in a thermally controlled chamber of $20 \mathrm{~mL}$ internal volume, where six sensors are placed: three thin films $\left(\mathrm{SnO}_{2}-\mathrm{MoO}_{3}\right.$ [57], $\mathrm{SnO}_{2}-\mathrm{WO}_{3}$ [58], 
$\mathrm{SnO}_{2}$ with Ag catalyzer [59]) and three sensors based on metaloxide nanowires (one of $\mathrm{SnO}_{2}$, two of $\mathrm{ZnO}$ ). With the $\mathrm{S} 3$ sensor array it is possible to detect the presence of the microorganisms. This is accomplished through the detection of certain organic volatile compounds (VOCs) produced during the metabolic activities of the microorganisms. In some cases, it is even possible to identify a specific species among a group of microorganisms [60].

The instrument was also provided with the auto-sampler headspace system HT280 (HTA srl, Brescia, Italy), supporting a 40 loading sites carousel and a shaking oven to equilibrate the sample headspace at $40{ }^{\circ} \mathrm{C}$ for $10 \mathrm{~min}$. The headspace $(2 \mathrm{~mL})$ was adsorbed and injected into the carrier flow at a speed of $4 \mathrm{~mL} / \mathrm{min}$. In order to have a reproducible sensor baseline, synthetic chromatographic air was used. A gas chromatography injector (kept at $40{ }^{\circ} \mathrm{C}$ to prevent any condensation) was adapted to produce a continuous flow rate of $10 \mathrm{~mL} / \mathrm{min}$ of air. The time needed to recover the baseline was $28 \mathrm{~min}$. The data analysis was carried out by means of principal component analysis (PCA).

\section{Acknowledgements}

The research leading to these results has received funding from the European Community's FP7-ICT-2013-10, MSP — MultiSensor-Platform for Smart Building Management under the project $n^{\circ} 611887$.

\section{References}

1. World Health Organization, Foodborne Disease Outbreaks. http://www.who.int/foodsafety/publications/foodborne_disease/outbreak guidelines.pdf (accessed April 28, 2017).

2. Taguchi, N. Gas-detecting device. U.S. Patent US000003631436A, Dec 28, 1971.

3. Gas Sensors - FIGARO USA, Inc.. http://www.figarosensor.com (accessed April 28, 2017).

4. Barsan, N.; Koziej, D.; Weimar, U. Sens. Actuators, B 2007, 121, 18-35. doi:10.1016/j.snb.2006.09.047

5. Mironova-Ulmane, N.; Kuzmin, A.; Sildos, I.; Pärs, M. Cent. Eur. J. Phys. 2011, 9, 1096-1099. doi:10.2478/s11534-010-0130-9

6. Sun, S. H.; Meng, G. W.; Zhang, G. X.; Gao, T.; Geng, B. Y.; Zhang, L. D.; Zuo, J. Chem. Phys. Lett. 2003, 376, 103-107. doi:10.1016/S0009-2614(03)00965-5

7. Weckhuysen, B. M.; Jehng, J.-M.; Wachs, I. E. J. Phys. Chem. B 2000, 104, 7382-7387. doi:10.1021/jp000055n

8. Rougier, A.; Portemer, F.; Quede, A.; El Marssi, M. Appl. Surf. Sci. 1999, 153, 1-9. doi:10.1016/S0169-4332(99)00335-9

9. Mozetič, M.; Cvelbar, U.; Sunkara, M. K.; Vaddiraju, S. Adv. Mater. 2005, 17, 2138-2142. doi:10.1002/adma.200500728

10. Jehng, J. M.; Wachs, I. E. Chem. Mater. 1991, 3, 100-107. doi:10.1021/cm00013a025
11. Shiguihara, A. L.; Bizeto, M. A.; Constantino, V. R. L. J. Braz. Chem. Soc. 2010, 21, 1366-1376. doi:10.1590/S0103-50532010000700024

12. Matsuoka, M.; Kitano, M.; Takeuchi, M.; Tsujimaru, K.; Anpo, M.; Thomas, J. M. Catal. Today 2007, 122, 51-61. doi:10.1016/j.cattod.2007.01.042

13. Abe, R.; Hara, M.; Kondo, J. N.; Domen, K.; Shinohara, K.; Tanaka, A. Chem. Mater. 1998, 10, 1647-1651. doi:10.1021/cm970825g

14. Lupan, O.; Ursaki, V. V.; Chai, G.; Chow, L.; Emelchenko, G. A.; Tiginyanu, I. M.; Gruzintsev, A. N.; Redkin, A. N. Sens. Actuators, B 2010, 144, 56-66. doi:10.1016/j.snb.2009.10.038

15. Nalage, S. R.; Mane, A. T.; Pawar, R. C.; Lee, C. S.; Patil, V. B. lonics 2014, 20, 1607-1616. doi:10.1007/s11581-014-1122-3

16. Degler, D.; Wicker, S.; Weimar, U.; Barsan, N. J. Phys. Chem. C 2015, 119, 11792-11799. doi:10.1021/acs.jpcc.5b04082

17. Barsan, N.; Rebholz, J.; Weimar, U. Sens. Actuators, B 2015, 207, 455-459. doi:10.1016/j.snb.2014.10.016

18. Staerz, A.; Berthold, C.; Russ, T.; Wicker, S.; Weimar, U.; Barsan, N. Sens. Actuators, B 2016, 237, 54-58. doi:10.1016/j.snb.2016.06.072

19. Kim, H.-J.; Lee, J.-H. Sens. Actuators, B 2014, 192, 607-627. doi:10.1016/j.snb.2013.11.005

20. Hübner, M.; Simion, C. E.; Tomescu-Stănoiu, A.; Pokhrel, S.; Bârsan, N.; Weimar, U. Sens. Actuators, B 2011, 153, 347-353. doi:10.1016/j.snb.2010.10.046

21. Yamazoe, N. Sens. Actuators, B 1991, 5, 7-19. doi:10.1016/0925-4005(91)80213-4

22. Gurlo, A.; Riedel, R. Angew. Chem., Int. Ed. 2007, 46, 3826-3848. doi:10.1002/anie.200602597

23. Hübner, M.; Simion, C. E.; Haensch, A.; Barsan, N.; Weimar, U. Sens. Actuators, B 2010, 151, 103-106. doi:10.1016/j.snb.2010.09.040

24. Zhang, J.; Zeng, D.; Zhu, Q.; Wu, J.; Huang, Q.; Xie, C. J. Phys. Chem. C 2016, 120, 3936-3945. doi:10.1021/acs.jpcc.5b12162

25. Standards - Air Quality - Environment - European Commission. http://ec.europa.eu/environment/air/quality/standards.htm (accessed April 28, 2017).

26. Bhowmik, B.; Manjuladevi, V.; Gupta, R. K.; Bhattacharyya, P. IEEE Sens. J. 2016, 16, 3488-3495. doi:10.1109/JSEN.2016.2530827

27. Nalage, S. R.; Chougule, M. A.; Sen, S.; Patil, V. B. J. Mater. Sci.: Mater. Electron. 2013, 24, 368-375. doi:10.1007/s10854-012-0758-x

28. Hoa, N. D.; El-Safty, S. A. Chem. - Eur. J. 2011, 17, 12896-12901. doi:10.1002/chem.201101122

29. Hotovy, I.; Rehacek, V.; Siciliano, P.; Capone, S.; Spiess, L. Thin Solid Films 2002, 418, 9-15. doi:10.1016/S0040-6090(02)00579-5

30. Khaleed, A. A.; Bello, A.; Dangbegnon, J. K.; Momodu, D. Y.; Madito, M. J.; Ugbo, F. U.; Akande, A. A.; Dhonge, B. P.; Barzegar, F.; Olaniyan, O.; Mwakikunga, B. W.; Manyala, N. J. Alloys Compd. 2017, 694, 155-162. doi:10.1016/j.jallcom.2016.09.310

31. Hotovy, I.; Huran, J.; Siciliano, P.; Capone, S.; Spiess, L.; Rehacek, V. Sens. Actuators, B 2001, 78, 126-132. doi:10.1016/S0925-4005(01)00802-4

32. Zeng, J.; Hu, M.; Wang, W.; Chen, H.; Qin, Y. Sens. Actuators, B 2012, 161, 447-452. doi:10.1016/j.snb.2011.10.059

33. Hadia, N. M. A.; Alqahtani, M. S.; Mohamed, S. H. Appl. Phys. A 2015, 119, 1261-1267. doi:10.1007/s00339-015-9090-7

34. Van, P. T. H.; Dai, D. D.; Van Duy, N.; Hoa, N. D.; Van Hieu, N. Sens. Actuators, B 2016, 227, 198-203. doi:10.1016/j.snb.2015.12.054

35. Park, S.; Kim, H.; Jin, C.; Choi, S.-W.; Kim, S. S.; Lee, C. Thermochim. Acta 2012, 542, 69-73. doi:10.1016/j.tca.2011.12.002 
36. Nisha, R.; Madhusoodanan, K. N.; Vimalkumar, T. V.; Vijayakumar, K. P. Bull. Mater. Sci. 2015, 38, 583-591. doi:10.1007/s12034-015-0911-2

37. Ahmad, M. Z.; Chang, J.; Ahmad, M. S.; Waclawik, E. R.; Wlodarski, W. Sens. Actuators, B 2013, 177, 286-294. doi:10.1016/j.snb.2012.11.013

38. Pawar, R. C.; Lee, J.-W.; Patil, V. B.; Lee, C. S. Sens. Actuators, B 2013, 187, 323-330. doi:10.1016/j.snb.2012.11.100

39. Rai, P.; Khan, R.; Ahmad, R.; Hahn, Y.-B.; Lee, I.-H.; Yu, Y.-T. Curr. Appl. Phys. 2013, 13, 1769-1773. doi:10.1016/j.cap.2013.06.005

40. Wang, J. X.; Sun, X. W.; Yang, Y.; Huang, H.; Lee, Y. C.; Tan, O. K.; Vayssieres, L. Nanotechnology 2006, 17, 4995-4998. doi:10.1088/0957-4484/17/19/037

41. Khuspe, G. D.; Sakhare, R. D.; Navale, S. T.; Chougule, M. A.; Kolekar, Y. D.; Mulik, R. N.; Pawar, R. C.; Lee, C. S.; Patil, V. B. Ceram. Int. 2013, 39, 8673-8679. doi:10.1016/j.ceramint.2013.04.047

42. Law, M.; Kind, H.; Messer, B.; Kim, F.; Yang, P. Angew. Chem. 2002, 114, 2511-2514. doi:10.1002/1521-3757(20020703)114:13<2511::AID-ANGE2511>3.0. $\mathrm{CO} ; 2-\mathrm{N}$

43. Zhang, J.; Wang, S.; Wang, Y.; Wang, Y.; Zhu, B.; Xia, H.; Guo, X.; Zhang, S.; Huang, W.; Wu, S. Sens. Actuators, B 2009, 135, 610-617. doi:10.1016/j.snb.2008.09.026

44. Van Hieu, N. Sens. Actuators, B 2010, 144, 425-431. doi:10.1016/j.snb.2009.02.043

45. Baik, N. S.; Sakai, G.; Miura, N.; Yamazoe, N. Sens. Actuators, B 2000, 63, 74-79. doi:10.1016/S0925-4005(99)00513-4

46. Wang, Z.; Hu, Y.; Wang, W.; Zhang, X.; Wang, B.; Tian, H.; Wang, Y.; Guan, J.; Gu, H. Int. J. Hydrogen Energy 2012, 37, 4526-4532. doi:10.1016/j.ijhydene.2011.12.004

47. Moon, H. G.; Jang, H. W.; Kim, J.-S.; Park, H.-H.; Yoon, S.-J. Sens. Actuators, B 2011, 153, 37-43. doi:10.1016/j.snb.2010.10.003

48. Dai, Z.; Dai, H.; Zhou, Y.; Liu, D.; Duan, G.; Cai, W.; Li, Y. Adv. Mater. Interfaces 2015, 2, 150167. doi:10.1002/admi.201500167

49. Sberveglieri, V.; Nunez Carmona, E.; Comini, E.; Ponzoni, A.; Zappa, D.; Pirrotta, O.; Pulvirenti, A. BioMed Res. Int. 2014, 529519. doi:10.1155/2014/529519

50. Comini, E.; Baratto, C.; Faglia, G.; Ferroni, M.; Vomiero, A.; Sberveglieri, G. Prog. Mater. Sci. 2009, 54, 1-67. doi:10.1016/j.pmatsci.2008.06.003

51. Mohammad, S. N. J. Chem. Phys. 2009, 131, 224702. doi:10.1063/1.3246169

52. Kaur, N.; Comini, E.; Zappa, D.; Poli, N.; Sberveglieri, G. Nanotechnology 2016, 27, 205701. doi:10.1088/0957-4484/27/20/205701

53. Steinhauer, S.; Brunet, E.; Maier, T.; Mutinati, G. C.; Köck, A.; Freudenberg, O.; Gspan, C.; Grogger, W.; Neuhold, A.; Resel, R. Sens. Actuators, B 2013, 187, 50-57. doi:10.1016/j.snb.2012.09.034

54. Zappa, D.; Bertuna, A.; Comini, E.; Molinari, M.; Poli, N.; Sberveglieri, G. Anal. Methods 2015, 7, 2203-2209. doi:10.1039/C4AY02637C

55. Byrappa, K.; Adschiri, T. Prog. Cryst. Growth Charact. Mater. 2007, 53, 117-166. doi:10.1016/j.pcrysgrow.2007.04.001

56. Fang, X.; Hu, L.; Huo, K.; Gao, B.; Zhao, L.; Liao, M.; Chu, P. K.; Bando, Y.; Golberg, D. Adv. Funct. Mater. 2011, 21, 3907-3915. doi:10.1002/adfm.201100743

57. Bontempi, E.; Zampiceni, E.; Sberveglieri, G.; Depero, L. E. Chem. Mater. 2001, 13, 2608-2612. doi:10.1021/cm010058s
58. Zampiceni, E.; Comini, E.; Faglia, G.; Sberveglieri, G.; Kaciulis, S.; Pandolfi, L.; Viticoli, S. Sens. Actuators, B 2003, 89, 225-231. doi:10.1016/S0925-4005(02)00469-0

59. Šetkus, A.; Baratto, C.; Comini, E.; Faglia, G.; Galdikas, A.; Kancleris, Ž.; Sberveglieri, G.; Senulien, D. Sens. Actuators, B 2004, 103, 448-456. doi:10.1016/j.snb.2004.05.004

60. Núñez Carmona, E.; Sberveglieri, V.; Comini, E.; Zappa, D.; Pulvirenti, A. Procedia Eng. 2014, 87, 1453-1456. doi:10.1016/j.proeng.2014.11.723

\section{License and Terms}

This is an Open Access article under the terms of the Creative Commons Attribution License

(http://creativecommons.org/licenses/by/4.0), which permits unrestricted use, distribution, and reproduction in any medium, provided the original work is properly cited.

The license is subject to the Beilstein Journal of

Nanotechnology terms and conditions:

(http://www.beilstein-journals.org/bjnano)

The definitive version of this article is the electronic one which can be found at: doi:10.3762/bjnano.8.122 